\title{
Sciendo
}

Administration, vol. 67, no. 3 (2019), pp. 65-89

doi: 10.2478/admin-2019-0021

\section{Fifty years of urbanisation in Ireland: Structural and spatial evolution of the urban hierarchy since Buchanan}

\author{
Des McCafferty \\ Department of Geography, Mary Immaculate College, \\ University of Limerick, Ireland
}

\begin{abstract}
In the fifty years since the publication of the Buchanan report, Regional Studies in Ireland, Ireland has transitioned from a rural to an urban society. Although a number of spatial plans have been introduced at regional and local levels, the growth of over 1.5 million people in the urban population has occurred in the absence of any strong national-level direction of spatial or settlement policy. This paper examines the nature of urbanisation in the halfcentury since 1966, by looking at the development of the urban hierarchy of cities and towns. Significant long-term changes in both the structure and the spatial expression of the urban hierarchy are identified, on the basis of which urbanisation is characterised as having been deconcentrated and decentralised. The paper identifies some implications of the observed shifts for contemporary policy concerns, and in particular the 2018 National Planning Framework.
\end{abstract}

Keywords: Urbanisation, urban hierarchy, spatial policy and planning, National Planning Framework 


\section{Introduction}

The publication of the National Planning Framework (Government of Ireland, 2018) represents just the third attempt at national-level spatial planning in the history of the state, following the Buchanan report (Colin Buchanan and Partners, 1968) and the National Spatial Strategy (NSS) (Government of Ireland, 2002). In a context of ongoing urbanisation of the Irish population over the past half-century, all three spatial plans in turn have assigned to Ireland's cities and towns - its urban system - a key role in promoting territorial development at the national and regional scales. To better enable the urban system to perform this role, each has sought to identify population centres that should be prioritised for investment - i.e. they have attempted to shape the hierarchy of cities and towns. However, the Buchanan report was never formally adopted as government policy, and significant problems were encountered with the implementation of the NSS, some of which were the result of external shocks, most notably the financial crisis of 2007-8, while others stemmed from deficiencies in governance and institutional arrangements at central government level (Moore-Cherry, 2019; O'Riordáin, 2013; Walsh, 2013). Consequently, the development of the urban hierarchy over the last fifty years can be said to have occurred in the absence of any strong or sustained spatial policy direction at national level. It is therefore instructive to examine how the process of urbanisation has unfolded in this period, and in particular how it has crystallised in the urban system, as such a perspective allows us to gain an understanding of the challenges that need to be overcome by the National Planning Framework.

Buchanan noted that the Irish urban hierarchy was characterised by marked imbalances in both its size structure and its spatial expression. The structural imbalance was evident in the lack of what he called medium-size towns, which he considered to be those with populations between 50,000 and 150,000; the spatial imbalance manifest in the complete absence of such towns in the north-western part of the state. In evaluating various alternative strategies for spatial development, he outlined the dilemma that these two characteristics together presented: strategies involving a greater concentration of investment in larger centres of population, which would be desirable in terms of maximising economic and employment growth, would do little for the development of the north-west. The political risks of proposing any such strategy were clear. The growth centre approach that Buchanan 
proposed was therefore a compromise strategy between the prevailing dispersionist policy of industrial development and policies that would focus on the larger centres of population. A hierarchy of growth centres was to be established, with centres selected mainly on the basis of their population size but also with regard to their location. Similar considerations underpinned the selection of centres to act as either 'gateways' or 'hubs' in the NSS, and, in the context of changed political and economic relationships between the state and Northern Ireland, the continuing weakness of the urban system in the north-west led to the designation of Letterkenny-Derry as a cross-border gateway.

This article examines the evolution of the Irish urban hierarchy since Buchanan, covering the years 1966-2016. While there have been a number of previous studies of temporal trends in the development of the Irish urban system (Cawley, 1991; Hourihan, 1992; Huff \& Lutz, 1995; Lutz, 2001; McCafferty, 2007; Pringle, 1980), none of these has adopted such a long time frame as in the present analysis. Taking the longer-term perspective allows us to uncover significant secular trends that cannot be identified from shorter-term analysis. The paper looks at changes in both aspects of the urban system identified by Buchanan and by the NSS as central to spatial planning - the size distribution of urban centres and their spatial distribution - and it attempts to identify some of the implications of these changes in terms of contemporary policy concerns. The next section addresses some methodological and data issues, and this is followed by the main empirical analysis. The fourth section of the paper will discuss the implications of the observed shifts for the sustainability of current patterns of urbanisation, while in the fifth and concluding section the scale and scope of the changes in the urban system proposed by the National Planning Framework will be considered briefly in light of the historical trends identified.

\section{Tracking urban development in Ireland - Methodological and data considerations}

The analysis set out in the central section of the paper is based on population data from the census of population for settlements with a population in excess of 1,500 persons or more. These settlements together constitute what the census refers to as the 'Aggregate Town Area'. Although the threshold of 1,500 population for urban areas is low by international standards, it is appropriate in the present context because of the recency of urbanisation in Ireland, and the continuing 
importance (in number if not in population) of smaller centres. Population data are used as the measure of the importance of towns, as these are the only data consistently available for urban areas since 1966. As will become clear later in the article, a somewhat different analysis might be conducted by looking at urban places as centres of employment rather than population, but unfortunately the data required to do this have only become available in recent censuses, with the introduction of geocoding of employment addresses.

One of the challenges for longitudinal analysis of the urban system is that the set of places constituting the Aggregate Town Area changes from one census to another, as settlement populations rise above, or occasionally drop below, the 1,500 threshold. Overall, as urbanisation has proceeded, the number of urban settlements has almost doubled, from 104 in 1966 to 200 in 2016. The latter number consists of 97 places with populations exceeding 1,500 at both the start and end of the period and a further 103 places that had exceeded the threshold by the end of the period. Seven of the 1966 places are not included in the 2016 data set, in two cases due to population dropping below the urban threshold, and in five cases because of amalgamation with other urban centres. Where analyses are based on the growth rates of urban centres over the full period, these have been calculated for 198 urban centres: the 200 places constituting the urban system in 2016, minus two centres (Annacotty, Co. Limerick, and Tullyallen, Co. Meath) for which no populations were recorded in 1966.

As well as change in the set of urban places over time, another challenge facing longitudinal studies of the urban system is that the categories which are useful for analysis may also change, making it difficult to decide on which set of categories to use. This paper focuses on the urban hierarchy, a concept which implies that urban areas can be arranged on the basis of their size into discrete bands or tiers. In reality, of course, urban areas tend to follow a continuum from largest centre to smallest, so that it is not obvious how many hierarchical tiers can be identified, or what their boundaries are in terms of population. Even if natural breaks in the size continuum can be identified, it is likely that these will change over time: there may be a gap in the continuum at, say, 50,000 population at one point in time but not at another. Though it is based on consideration of the size continuum across time, no claims are made for the hierarchical division chosen in this paper. For most analyses five tiers are identified. These are: centres with populations between 1,500 and 5,000 (labelled 'small towns'); centres with populations from 5,000 to 10,000 ('medium-size 
towns'); places with 10,000 to 50,000 population ('large towns'); centres with populations between 50,000 and 250,000 ('cities'); and places above 250,000 population, of which there is just one, Dublin. For some analyses a sixth category is identified. These are settlements with populations below the urban cut-off of 1,500, but which had exceeded the cut-off by 2016. These are referred to as 'rural villages'.

Longitudinal analysis based on population data throws up yet another issue, namely that the delimitation of individual urban areas has changed over time. The census distinguishes between two types of urban area: those with a local council (formerly town commissioners or urban district councils; town councils from 2002) and therefore a legally defined boundary, and those without. For towns without legal status, known as census towns, as well as for the 'environs' or suburbs of legal towns, boundaries have to be established for each census, and this is done broadly on the basis of delimiting the continuous built-up area of the settlement. Prior to 1971, this task was carried out by the Central Statistics Office (CSO) in conjunction with the various local authorities, with therefore no guarantee of consistency in the approach used (CSO, 1972, p. viii). For the 1971 census of population, nationally standardised criteria for delimiting boundaries were applied centrally by the CSO, and these remained unchanged until 2011, when the 'proximity' criterion for deciding whether a dwelling fell within the town boundary was reduced from 200 metres to 100 metres distance to the nearest dwelling within the boundary (CSO, 2012, p. 153). The tightening of boundary definitions in 2011 may be expected to have resulted in a relative understatement of town populations compared to earlier censuses.

However, the most significant change came with the Local Government Reform Act of 2014, under which the eighty town councils were abolished. With the legally defined boundaries of these towns no longer meaningful or relevant, the opportunity was taken by the CSO to define new settlement boundaries for the towns in question, applying the same criteria as used for census towns. While this has introduced a consistent approach to boundary definition across all towns, and provided the basis for better analysis going forward, it also means that comparison of urban populations between the 2011 and 2016 censuses is difficult. Among the seventy-five former legal towns with populations over 1,500, fifty-six towns ( 75 per cent) lost area as a result of the redefinition of boundaries, some of them quite significantly. The case of one such town - Ballina, Co. Mayo - is illustrated in Table 1. The town lost more than half of its area as a 
result of the boundary redefinition, and while much of the area excluded from the new boundary was sparsely populated, nevertheless an 8 per cent decrease in population was recorded. It is almost certain that this is purely an artefact of the boundary change, rather than reflecting an actual decline in the town population. The problem is that the 'real' population change remains unknown.

Table 1: Effects of the $\mathbf{2 0 1 6}$ boundary redefinition, Ballina, Co. Mayo

\begin{tabular}{lrrr}
\hline & 2011 & 2016 & $\begin{array}{c}\text { Percentage } \\
\text { change }\end{array}$ \\
\hline Area of settlement (sq. km) & 15.0 & 6.7 & -55 \\
Population & 11,086 & 10,171 & -8 \\
Population density (persons/sq. km) & 741 & 1,509 & +104 \\
\hline
\end{tabular}

Source: CSO (2012, Table CD116; 2017a, Table E2014) and author's calculations.

These changes in town definitions over the years should be borne in mind in interpreting the analysis that follows. Most obviously, trends in urbanisation since 2011, and comparisons between the period 201116 and previous intercensal periods, need to be treated with a degree of caution. Caution is also required in interpreting structural shifts in the urban hierarchy, because of the fact that not all size categories of towns were affected to the same degree by the post-2014 boundary changes. Table 2 illustrates the distribution by size category of legal towns that lost area, and suggests that the biggest demographic impact of the post-2014 boundary changes is likely to have been in the large town category. There is a strong likelihood that population growth in such towns between 2011 and 2016, and indeed between 1966 and 2016, is underestimated in the analyses that follow.

\section{Structural and spatial changes in the urban hierarchy}

This section will examine changes in, first, the size distribution of urban centres over the period of interest, and, second, the spatial distribution of centres. In each case, analysis will move from an initial focus on the process of urban growth, examining trends in growth rates for individual urban centres, to a consideration of the outcome of differential urban growth in terms of macro trends in urbanisation by settlement size category and regional location, respectively. 
Table 2: Former legally defined towns losing area following boundary redefinition, by size class

\begin{tabular}{lcccc}
\hline Size category & $\begin{array}{c}\text { Total number } \\
\text { of towns } \\
2016\end{array}$ & $\begin{array}{c}\text { Number } \\
\text { of legally } \\
\text { defined towns } \\
\text { (pre 2014) }\end{array}$ & $\begin{array}{c}\text { No. of legal } \\
\text { towns losing } \\
\text { area }\end{array}$ & $\begin{array}{c}\text { As \% of all } \\
\text { towns in the } \\
\text { category }\end{array}$ \\
\hline$>250,000$ & 1 & 0 & 0 & 0 \\
$50,000-250,000$ & 4 & 0 & 0 & 0 \\
$10,000-50,000$ & 41 & 33 & 24 & 59 \\
$5,000-10,000$ & 40 & 23 & 14 & 35 \\
$1,500-5,000$ & 114 & 19 & 18 & 16
\end{tabular}

Source: Author's calculations based on CSO (2012, Table CD116; 2017a, Table E2014).

\section{Urban growth rates and the structure of the urban hierarchy}

The half-century from 1966 to 2016 was a period of significant urbanisation. In 1966 Ireland was still predominantly rural, with less than half of the population -1.42 million out of a total population of 2.88 million (49 per cent) - residing in the Aggregate Town Area (CSO, 1967, Table 7). By 2016 the urban-based population had more than doubled, outstripping the overall growth in population of 65 per cent. As a result, almost two-thirds (63 per cent) of the population was recorded as urban in 2016 - just under 3 million persons out of a total of 4.76 million (CSO, 2017a, Table E2004). Urban population grew most rapidly in the period from 1966 to 1981, and again between 1996 and 2011 (Figure 1). It is notable that both were periods of relatively strong economic growth, the first ushered in by the First Programme for Economic Expansion 1958-63, and the second corresponding to the Celtic tiger period. It is not coincidental that it was during these periods of growth that the first attempts at national-level spatial planning were undertaken - the Buchanan report in 1968 and the NSS in 2002.

Urbanisation has been associated with widely differing rates of growth across urban centres. Some centres experienced exceptionally high growth between 1966 and 2016, multiplying their populations many fold. For example, Ashbourne in Co. Meath grew from a rural village of 139 persons into a large town of almost 13,000. On the other hand three towns - Clones, Kilrush and Templemore - lost population. In general, differences in growth rates vary according to population size, and the trend has been for smaller places to record 
Figure 1: Average annual growth rate of urban population

3.00

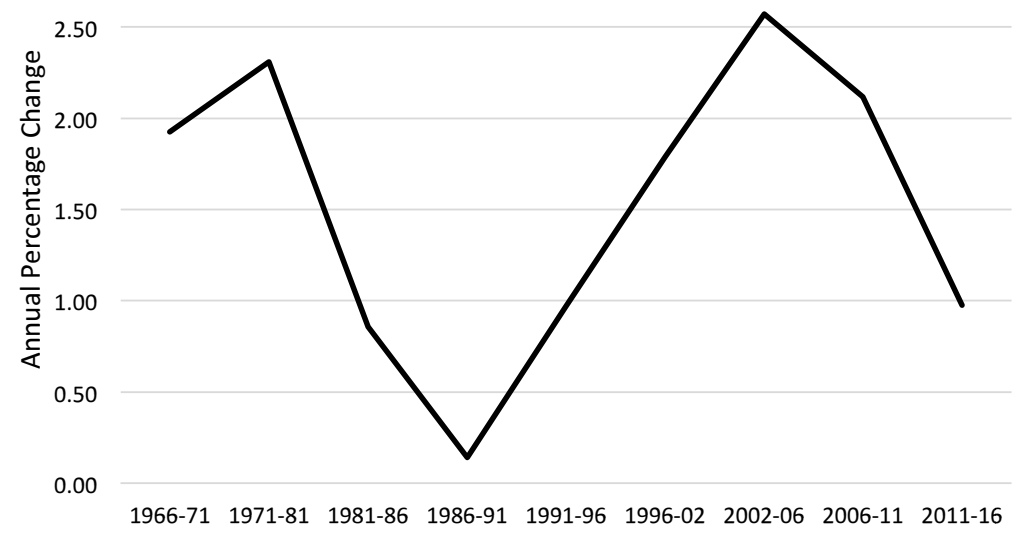

Source: Author's calculations. Urban population is the population in the Aggregate Town (or Urban) Area at each census.

the highest rates of population growth. This is borne out by two different analyses for the 198 urban centres with 1,500 or more population in 2016 for which a growth rate between 1966 and 2016 can be calculated. First, the correlation between population size in 1966 and average annual growth rate over the ensuing period is derived. To allow for non-linearity in the relationship, Spearman's rank correlation coefficient is used, and this is found to be strongly negative, with $r_{\mathrm{s}}=-0.58$ (significant at the .01 level). This finding is confirmed by an analysis of average annual growth rates by town size category. For this analysis, urban centres are divided on the basis of their 1966 population into the six size categories or hierarchical tiers set out in the methodology, and median growth rates are calculated for each category (Table 3). This again shows an inverse relationship between size and growth rate, with median growth rates trending upwards as size decreases. Thus, the median growth rate for rural villages (places that were below the 1,500 population threshold in 1966) was four times the median for the two second-tier centres that had in excess of 50,000 population at that time (Cork and Limerick), and almost three times the median for large towns with between 10,000 and 50,000 population. It is notable in passing that Cork and Limerick also performed poorly relative to Dublin (the only centre 
with population in the $250,000+$ category), a theme that will be revisited in the next section of the paper.

Table 3: Median of average annual population growth rates, 1966-2016, by size class of urban area

\begin{tabular}{llcc}
\hline $\begin{array}{l}\text { Size category 1966 } \\
\text { (population range) }\end{array}$ & Descriptor & $N$ & $\begin{array}{c}\text { Median of average } \\
\text { annual growth rates }\end{array}$ \\
\hline$>250,000$ & Dublin & 1 & 1.61 \\
$50,000-250,000$ & Other cities & 2 & 1.29 \\
$10,000-50,000$ & Large towns & 11 & 1.89 \\
$5,000-10,000$ & Medium-size towns & 18 & 2.26 \\
$1,500-5,000$ & Small towns & 66 & 2.01 \\
$<1,500$ & Rural villages & 100 & 5.25 \\
All settlements & & 198 & 2.98
\end{tabular}

Source: Author's calculations from CSO (1967; 2017a); average annual growth rate is the percentage rate of change divided by fifty (number of years).

To some extent the observed relationship between size and growth rates is to be expected, in that higher growth rates are more easily attained by smaller settlements that are growing from a low base. Construction of a single large housing estate in a rural village or small town - where housing demand is typically generated by employment growth in a nearby city or large town - can result in population growing by a multiple of the original level. The more important issue for the present analysis is the extent to which the wide variation in urban growth rates has impacted on and reshaped the urban system, by allowing smaller places to transition into higher population bands; in effect to ascend the urban hierarchy. The extent of this phenomenon is examined in Table 4, which cross-classifies the 198 urban centres in 2016 according to their hierarchical level in both 2016 and 1966, using the same population size categories as used previously. The table shows that just 44 centres remained in the same size band across the period (those in cells along the diagonal of the matrix), with 154 moving into a higher size category as a result of population growth. Of these, 125 places moved up one category, the majority of which (84) were centres that were below the urban threshold in 1966, but that had emerged as small towns (1,500 to 5,000 population) by 2016. A further 24 places, transitioned across two categories, the majority of these (13) being small towns in 1966 that grew into large towns (10,000 to 50,000 population) by 2016 . Examples of such places 
are Swords, Celbridge, Tramore and Letterkenny. The other 11 places transitioning across two tiers of the urban system were rural villages in 1966 that grew into medium-sized towns (5,000 to 10,000 population). Examples here are Donabate, Ratoath, Clane and Carrigtwohill, none of which had populations in excess of 500 in 1966. Acknowledging that the narrower population range of the smaller size categories makes it easier for places in these categories to transition upwards, nevertheless this analysis highlights some instances of remarkable transformation. The most dramatic of all are the 5 rural villages that transitioned across 3 tiers of the urban hierarchy to emerge as large towns by the end of the period. Arranged in descending order of their growth rates, these are Ashbourne, Carrigaline, Leixlip, LaytownBettystown and Maynooth.

It is notable that most of the upwardly mobile centres named above lie in close proximity to the cities of Dublin, Cork or Waterford. None of the centres in question were designated for rapid population increase in either the Buchanan report or the NSS. However, in the case of Carrigaline, growth was the result of a planned strategy of expansion under the Cork Land Use and Transportation Study (LUTS) in the 1970s, and subsequently the Cork Area Strategic Plan (CASP) introduced in 2001 to help contain the sprawl of Cork city, which Walsh $(2013$, p. 33) acknowledges as an exemplary attempt at strategic spatial planning at the local level. The implications of the growth of towns in the commuting belts of the cities will be explored in more detail in section four of the paper.

Table 4: Changes in the size classification of urban areas, 1966-2016

\begin{tabular}{lrrrrrr}
\hline \multicolumn{7}{c}{ Size category 2016} \\
\hline $\begin{array}{l}\text { Size } \\
\text { category }\end{array}$ & $1,500-$ & $5,000-$ & $10,000-$ & $50,000-$ & $>250,000$ & $\begin{array}{c}\text { All } \\
\text { urban } \\
1966\end{array}$ \\
\hline places
\end{tabular}

Source: Author's calculations from CSO (1967, Tables 13, 19; 2017a, Table E2014). 
The outcome of these processes of urban growth has been a significant structural change in the urban system. This is revealed in Table 5, which compares the urban hierarchy of 1966 to that of 2016, in terms of both the number of centres and the total urban population by size category. The largest expansion has been in the category of large towns, i.e. those with populations between 10,000 and 50,000. Both the number of such centres and the total population resident in them roughly quadrupled over the period, and the category increased its share of urban population by 13 percentage points (from 13 per cent to 26 per cent). As noted in the earlier discussion of data considerations, it is likely that the large town component of the urban system in 2016 is, in fact, underestimated. The expansion of towns in this category has been largely driven by the growth of smaller places. Thus, of the total of 41 large towns in 2016, 14 were medium-size towns in 1966, 13 were small towns, and 5 were rural villages. While Dublin expanded its population by 80 per cent over the period, and accounted for one-third of the total expansion in urban population, it lagged the overall growth of urban population (110 per cent) and so the capital's share of the urban total decreased by 7 percentage points (from 46 per cent to 39 per cent). A large part of Dublin's growth was due to the absorption of a number of settlements that in 1966 were separately enumerated in the census. The most significant of these are Dún Laoghaire and the four 'new towns' recommended to be developed on Dublin's western fringe in the Wright report of 1967: Clondalkin, Tallaght, Lucan and Blanchardstown. Together these five urban areas contained a population of over 96,000 in 1966.

Buchanan's concerns about the size distribution of urban places centred on the paucity of middle-ranking centres of population, and their small size relative to Dublin. Although he described this pattern as 'unusual' (Colin Buchanan and Partners, 1968, p. 5), urban systems that are dominated by a single urban centre are in fact common enough to have been designated as a distinct category of 'primate' urban systems (Jefferson, 1939). Examples of European states with primate urban systems include Hungary, Latvia, Austria and Denmark, all of which are dominated by their capital cities: Budapest, Riga, Vienna and Copenhagen, respectively. The factors shaping urban size distributions are still not well understood (Fujita et. al. 1999, p. 215), but among the influences that have been considered important are a country's experience of colonialism, its level of political integration, size and geographical diversity, and the degree of openness/export-orientation of the economy. To conclude the analysis 
Table 5: The urban hierarchy, 1966 and 2016

\begin{tabular}{|c|c|c|c|c|c|c|}
\hline & \multicolumn{2}{|c|}{1966} & \multicolumn{2}{|r|}{2016} & \multirow{2}{*}{$\begin{array}{c}\text { Share } \\
\text { of urban } \\
\text { growth }\end{array}$} & \multirow{2}{*}{$\begin{array}{l}\text { Change in } \\
\text { urban } \\
\text { population } \\
\text { share } \\
\text { (percentage } \\
\text { points) }\end{array}$} \\
\hline $\begin{array}{l}\text { Size category } \\
\text { (population range) }\end{array}$ & $N$ & $\begin{array}{l}\text { Population } \\
\text { (000s) }\end{array}$ & $N$ & $\begin{array}{l}\text { Population } \\
\text { (000s) }\end{array}$ & & \\
\hline$>250,000$ & 1 & 650 & 1 & 1,173 & 33 & -7 \\
\hline $50,000-250,000$ & 3 & 268 & 4 & 436 & 11 & -4 \\
\hline $10,000-50,000$ & 11 & 182 & 41 & 779 & 38 & +13 \\
\hline $5,000-10,000$ & 19 & 123 & 40 & 294 & 11 & +1 \\
\hline $1,500-5,000$ & 70 & 196 & 114 & 304 & 7 & -4 \\
\hline All urban areas & 104 & 1,419 & 200 & 2,986 & 100 & 0 \\
\hline
\end{tabular}

Source: Author's calculations from CSO (1967, Table 13; 2017a, Table E2014). Note: The numbers of centres for each year do not correspond to the column and row totals in Table 4 due to the exclusion from the latter of centres without a recorded population in both 1966 and 2016.

of trends in the size distribution of urban centres since Buchanan, we can calculate a number of different primacy ratios. Figure 2 illustrates the trends in two such measures: P1 is the ratio of Dublin's population to that of the second largest city (Cork), and P2 is the ratio of the capital's population to the combined population of the other cities (Cork, Limerick, Galway and Waterford). As throughout this paper, populations are for the continuous built-up areas, as defined by the $\mathrm{CSO}$ at each census, and it should be noted that fluctuations in values can occur when previously distinct settlements are incorporated into the built-up area of a city. Thus, the incorporation of Blanchardstown, Clondalkin, Dún Laoghaire and Tallaght into Dublin in 1981 resulted in a marked increase in P1, while the incorporation of Glanmire into Cork in 1986 produced a sharp decrease in P1. These fluctuations notwithstanding, the figure shows that, over the long term, Dublin has maintained a high level of primacy relative to Cork, with a P1 value which has remained above 5.0, and indeed has trended upwards over time. To put this in perspective, if urban sizes in Ireland followed the rank-size rule (Zipf, 1949), which has been considered indicative of more balanced urban systems (Flanagan, 2010), P1 would have a value of 2.0. Relative to the four provincial cities combined, Dublin's primacy has declined slightly, from a P2 value of 3.1 in 1966 to 2.7 in 2016. However, on this measure also the capital city's dominance remains strong: if Irish city populations followed the rank-size rule, 
the P2 ratio would be 0.78. Furthermore, as discussed in the concluding section and elsewhere (McCafferty, 2007), primacy ratios and other measures based on settlement populations arguably understate the dominance of Dublin in the Irish urban system. For now, it is sufficient to conclude that the pattern of urban growth in the period since Buchanan has done little to lessen Dublin's dominance relative to the other cities.

Figure 2: Primary ratios, 1966-2016

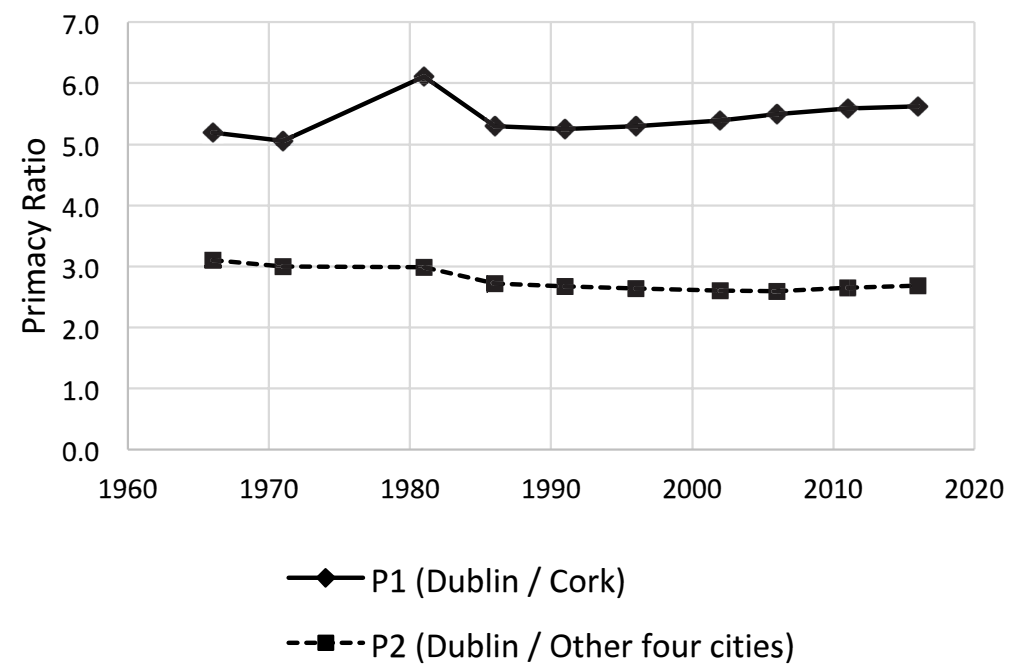

Source: Author's calculations. See text for definition of cities.

\section{Spatial shifts in the urban hierarchy}

These considerations of differential urban growth rates and their impact on the structure of the urban hierarchy tell only part of the story of change. To get the full picture, including the part of the picture that is most relevant to spatial planning, we need to consider the geography of the urban system.

As a preliminary step in this, we will again start with the growth rates of individual centres of population, but this time the focus is on the relationship between growth and the location, rather than the size, of the urban centre. An analysis along these lines was carried out in Ireland by Lutz (2001), who used regression analysis to examine the relationship between the growth of towns for various intervals of time in the twenty-five years from 1966 to 1991 and a battery of eighteen explanatory variables. These included measures of the sectoral 
structure of employment in each town, the town's age structure, and its relative location measured in terms of its distance from Dublin and the cities of Cork and Limerick. The measurement of distance from each of the three cities was generalised: in each case a town was simply assigned to one of six zones based on its straight-line distance from the city in question. Lutz found that the best predictor of a town's growth was its zonal distance from Dublin, which was negatively associated with growth - i.e. lower growth rates were associated with greater distance. This negative relationship held for all intercensal time periods from 1966 onwards, except 1981 to 1986, though it was not statistically significant in the periods $1971-81$ and 1981-91.

A scaled-down version of Lutz's analysis is presented in Table 6, which gives findings from a regression analysis of average annual growth rates (the dependent variable) against distance from Dublin (the independent variable) for all intercensal periods in the 50-year interval of interest here, as well as for the period as a whole. Distance is again straight-line distance, measured in kilometres, but logarithmically transformed on the grounds that the effect of distance on growth could be expected to attenuate with increasing distance. The towns included in the analysis are again the 198 centres with 1,500 or more population in 2016 for which a growth rate between 1996 and 2016 can be calculated. Despite the obvious shortcoming in the use of straight-line distance - the fact that it does not take into account spatial variability in access to key transport infrastructures such as railway lines and major roads - it is notable that the results replicate the Lutz analysis in showing that distance from Dublin has been negatively associated with urban population growth. This is indicated by the $b$ coefficient, which is negative and statistically significant for all intercensal periods. The relationship was strongest between 1966 and 1991, weakening somewhat thereafter. Nevertheless, it remains strong for the period taken as a whole, as indicated by the $\mathrm{R}^{2}$ value 0.352 .

Distance from Dublin is just one, somewhat basic, measure of location. A more elaborated geographical analysis can be conducted by looking at urban growth rates by region, using the post-2014 NUTS 3 regions (Table 7). This is similar to the analysis of growth rates by population size presented in Table 3, but with region now replacing size category as the explanatory variable. The results show statistically significant differences in urban growth rates across regions, with the strong performance of the Greater Dublin Area (GDA), consisting of the Dublin and Mid-East regions, particularly notable. By far the highest growth rates are observed in the Dublin region, which 
Table 6: Regression analysis of annual average growth rate against distance from Dublin

\begin{tabular}{lccl}
\hline Period & $b$ coefficient & Significance & $R^{2}$ \\
\hline $1966-1971$ & -6.455 & .000 & .266 \\
$1971-1981$ & -8.742 & .000 & .315 \\
$1981-1986$ & -2.916 & .000 & .226 \\
$1986-1991$ & -2.053 & .000 & .300 \\
$1991-1996$ & -1.654 & .000 & .100 \\
$1996-2002$ & -1.879 & .002 & .069 \\
$2002-2006$ & -3.546 & .001 & .082 \\
$2006-2011$ & -1.670 & .004 & .048 \\
$2011-2016$ & -1.384 & .000 & .120 \\
$1966-2016$ & -9.103 & .000 & .352 \\
\hline
\end{tabular}

Source: Author's analysis.

corresponds to the old Dublin County (median growth rate of 17.6 per cent per annum), but it should be pointed out that the median for this region is somewhat inflated by the fact that, as noted earlier, five of the region's urban centres were absorbed into the Dublin urban area during the period. Had these centres continued to be separately enumerated it is most likely that the median centre growth rate would have been lower. The second-highest median growth rate (7.9 per cent) was recorded for the Mid-East region, consisting of Counties Louth, Meath, Kildare and Wicklow. In comparison, growth rates in all other regions are low, with a median for the twenty-two centres in the Mid-West region (Counties Clare, Limerick and Tipperary) of just 1.3 per cent. Differentials in urban growth between regions can be further explored by looking at the regional distribution of the 154 centres of population identified earlier as having ascended the urban hierarchy. Table 8 shows that fifty-six of these settlements were located in either the Mid-East region (forty-three) or the Dublin region (thirteen). If we focus on the twenty-nine centres that transcended two or more tiers of the hierarchy, no less than twentytwo were located in the GDA: fourteen in the Mid-East, and eight in the Dublin region. Clearly, it is the growth of urban centres in the GDA that is driving the observed regional differentials in urban growth rates.

The outcome of differential urban growth, in terms of the changing regional expression of the urban system, is illustrated in Table 9. The table reveals the spatially uneven incidence of urbanisation in the period 1966-2016. Unsurprisingly, in view of the findings reported 
Table 7: Median of average annual population growth rates, 19662016, for urban centres by region

\begin{tabular}{lcc}
\hline $\begin{array}{l}\text { NUTS 3 Region } \\
(2014)\end{array}$ & $N$ & $\begin{array}{c}\text { Median of annual } \\
\text { average growth rates }\end{array}$ \\
\hline Dublin & 14 & 17.60 \\
Mid-East & 47 & 7.91 \\
Border & 25 & 2.57 \\
West & 20 & 2.26 \\
Midland & 17 & 2.25 \\
South-East & 20 & 2.16 \\
South-West & 33 & 1.81 \\
Mid-West & 22 & 1.27 \\
Total & 198 & 2.98 \\
\hline
\end{tabular}

Source: Author's analysis.

Table 8: Movement of towns up the urban hierarchy by region, 1966-2016

\begin{tabular}{|c|c|c|c|c|c|c|c|c|}
\hline $\begin{array}{l}\text { NUTS } 3 \\
\text { region }\end{array}$ & $\begin{array}{r} \\
\text { Small } \\
\text { town }\end{array}$ & $\begin{array}{c}\text { Rural villag } \\
\text { to: } \\
\text { Medium } \\
\text { town }\end{array}$ & $\begin{array}{l}g e \\
\text { Large } \\
\text { town }\end{array}$ & $\begin{array}{c}\text { Small } \\
\text { to } \\
\text { Medium } \\
\text { town }\end{array}$ & $\begin{array}{l}\text { town } \\
\text { Large } \\
\text { town }\end{array}$ & $\begin{array}{c}\text { Medium } \\
\text { town to: } \\
\text { Large } \\
\text { town }\end{array}$ & $\begin{array}{c}\text { Large } \\
\text { town to: } \\
\text { City }\end{array}$ & Total \\
\hline Dublin & 4 & 4 & & 1 & 4 & & & 13 \\
\hline Mid-East & 22 & 6 & 4 & 4 & 4 & 3 & & 43 \\
\hline Border & 13 & & & 3 & 2 & & & 18 \\
\hline West & 10 & & & 4 & & 2 & 1 & 17 \\
\hline Midland & 7 & & & 2 & 1 & 3 & & 13 \\
\hline South-East & 9 & & & 2 & 1 & 2 & 1 & 15 \\
\hline South-West & 11 & 1 & 1 & 4 & 1 & 3 & & 21 \\
\hline Mid-West & 8 & & & 5 & & 1 & & 14 \\
\hline Ireland & 84 & 11 & 5 & 25 & 13 & 14 & 2 & 154 \\
\hline
\end{tabular}

Source: Author's analysis.

above, urbanisation has been strongly concentrated in the GDA, which accounted for over half (57 per cent) of the entire urban expansion. In contrast, the Border and West regions, which make up the Northern and Western NUTS 2 (regional assembly) region, absorbed just 12 per cent of the urban growth. On closer inspection it is the performance of the Mid-East region which is the more remarkable within the GDA. Reflecting the performance of the Dublin urban area, the growth of urban population in the Dublin region (+73 per cent) was somewhat less than in the country as a 
whole (+110 per cent), so that the region's share of urban population contracted. In the Mid-East region, however, the urban population expanded almost five-fold (from 98,000 to 446,000), resulting in a large increase in the region's share of urban population, which grew by eight percentage points. This growth was underpinned by a remarkable increase in the number of urban centres in the region, which more than trebled (from fifteen to forty-eight) as compared to approximately a doubling at national level. The thirty-three rural villages that grew into urban centres include six medium-size towns in 2016 (Blessington, Clane, Dunboyne, Kilcock, Ratoath and Sallins) and four large towns (Ashbourne, Laytown-Bettystown, Leixlip and Maynooth).

Table 9: Distribution of urban centres and urban population by region, 1966 and 2016

\begin{tabular}{|c|c|c|c|c|c|c|}
\hline & \multicolumn{2}{|c|}{1966} & \multicolumn{2}{|c|}{2016} & \multirow{2}{*}{$\begin{array}{c}\text { Share of } \\
\text { urban } \\
\text { growth }\end{array}$} & \multirow[b]{2}{*}{$\begin{array}{c}\text { Change in } \\
\text { urban } \\
\text { share } \\
\text { (percentage } \\
\text { points) }\end{array}$} \\
\hline $\begin{array}{l}\text { NUTS } 3 \text { Region } \\
\text { (2014) }\end{array}$ & $N$ & $\begin{array}{c}\text { Urban } \\
\text { population } \\
(000 s)\end{array}$ & $N$ & $\begin{array}{c}\text { Urban } \\
\text { population } \\
(000 \mathrm{~s})\end{array}$ & & \\
\hline Dublin & 11 & 760 & 14 & 1,315 & 35 & -10 \\
\hline Mid-East & 15 & 98 & 48 & 446 & 22 & +8 \\
\hline Border & 11 & 42 & 25 & 115 & 5 & +1 \\
\hline West & 10 & 61 & 20 & 168 & 7 & +1 \\
\hline Midland & 10 & 50 & 17 & 132 & 5 & +1 \\
\hline South-East & 11 & 91 & 20 & 200 & 7 & 0 \\
\hline South-West & 21 & 200 & 33 & 393 & 12 & -1 \\
\hline Mid-West & 15 & 118 & 23 & 218 & 6 & -1 \\
\hline All urban areas & 104 & 1,419 & 200 & 2,986 & 100 & 0 \\
\hline
\end{tabular}

Source: Author's analysis.

A final insight into the geography of urbanisation in Ireland in the period from 1966 to 2016 is provided by calculating the median centre of the distribution of urban centres. The focus here is on the morphology or spatial structure of the urban system and so the simple (unweighted) median centre is used. This represents the centre of gravity of the set of urban places (rather than of urban population), and as such its location could be expected to be relatively stable over time. For example, if all urban growth was accommodated in existing urban centres, then, even if growth rates varied across centres, there would be no change in this measure. Interestingly, this calculation 
shows that the median centre has in fact moved significantly. In 1966 it was located close to the village of Kinnity in south Offaly; by 2016 it had shifted twenty-two kilometres north and east (i.e. in the direction of Dublin) to now lie two kilometres south and east of the village of Killeigh on the Offaly-Laois border. This shift is again indicative of the large number of new urban centres appearing in the Mid-East region due to the growth of previously rural settlements.

\section{Assessing the changes in the urban hierarchy}

The structural and spatial outcomes of urban growth in the period 1966 to 2016 can be characterised as a pattern of deconcentrated and decentralised urbanisation: deconcentrated in that urban expansion was greatest in large towns $(10,000$ to 50,000 population) rather than Dublin or the other cities; decentralised in that the greatest increase in regional share of urban population occurred not in the Dublin region but in the adjoining Mid-East, which was also the region showing the greatest increase in the number of urban centres. This section of the paper will briefly consider how we might assess these developments of the urban hierarchy from the point of view of spatial planning, and in particular the goals of the NPF. The key question is whether the evolutionary pattern, in both its hierarchical and spatial/regional aspects, has advanced the prospects for sustainable and regionally balanced development? To attempt to answer this question, we will examine developments, firstly in terms of what might be considered desirable from the standpoint of economic development, and secondly in terms of the somewhat broader concept of sustainability.

Reflecting the priorities of the Second Programme for Economic Development 1964-70, Buchanan's focus was on the cities and large towns as manufacturing centres - i.e. as places to concentrate industrial investment. In the intervening fifty years, manufacturing has become less important to the economic base of urban areas in developed countries, including Ireland, yet cities remain crucial to regional development, as centres of creativity and innovation, knowledge-intensive services and overall economic growth (Clark et al., 2018). In the context of the new urban economy, attention, particularly within Europe, has been focused on the potential of intermediate-sized or 'second-tier' urban centres to contribute to economic development (ESPON, 2012), in particular within the spatial framework of polycentric urban regions (Commission of the 
European Communities, 1999). Dijkstra (2013) has produced both theoretical and empirically based arguments in favour of the development of second-tier cities, which have been defined simply as 'the group of largest cities in a country excluding the capital' (ESPON, 2016, p. 2). He suggests that both highly dispersed urbanisation (many small places) and highly concentrated urbanisation (one very large place) are economically inefficient. Instead, he argues, an urban system with a continuum of urban sizes is more desirable, because such a continuum maximises locational choice for both firms and individuals. These theoretical considerations for policies to favour development of second-tier cities are closely related to the concept of an optimum city size at which output per capita and labour productivity are maximised. The existence of an optimum size is based on arguments about the emergence of agglomeration diseconomies related inter alia to congestion costs as cities grow beyond their theoretical optimum size. Support for the existence of an optimum city size is provided by an OECD (2006) report, which suggests that the relationship between urban size and productivity follows an inverted U-shaped pattern; in other words, that productivity is highest in medium-size cities. Dijkstra's own empirical work on second-tier cities in Europe shows that such cities have been performing better than larger centres of population in the period since the crash, and he therefore argues for public investment in them. Further support for this argument comes from empirical findings reported by Dijkstra et al. (2013) and Parkinson et al. (2015).

The second-tier cities were central to Buchanan's recommendation of a growth centre policy, in which Cork and Limerick-Shannon were designated as national growth centres, and formed the top of his threetier roster of growth centres. Not surprisingly, the failure to implement a more spatially selective approach to investment at national level has meant that these centres, as a group, have performed poorly in terms of population growth in the intervening period. This is borne out by Figure 3, which compares the urban size pattern in 1966 to that in 2016 for all centres with population in excess of 10,000 , and shows that the second-tier cities formed a clearer grouping, and had a stronger relative position in the urban hierarchy, in 1966. There has been no discernible convergence between these cities and Dublin, but the gap between them and the large towns narrowed considerably. This is consistent with findings reported by Brady (2016), who examined the performance of Cork, Limerick, Galway and Waterford in terms of both population and jobs growth in the period 1991-2011. He shows 
that, in population terms, the second-tier cities underperformed both individually and collectively compared to towns with $10,000+$ population. Compared to Dublin, they performed well in population growth between 1991 and 2001, but fell back relative to the capital in 2001-11 - i.e. in the first ten years following the introduction of the NSS. In summary, if second-tier cities are indeed important to national development, then the evolution of the urban system since 1966 may be assessed negatively on these grounds.

Figure 3: Rank-size curves, 1966 and 2016, for all centres with 10,000 population and over

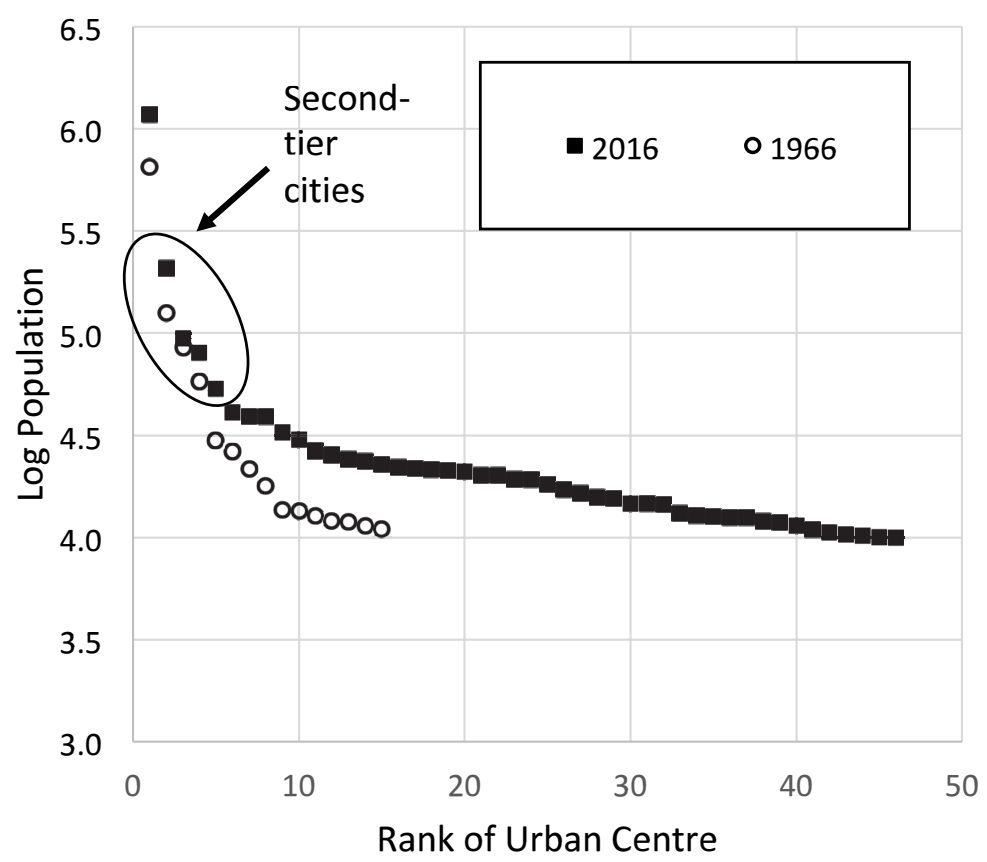

Source: Author's calculations based on CSO (1967, Table CD116; 2017a, Table E2014).

A second basis for assessing urban development since the late 1960s is provided by the concept of sustainable development, which is one of the key policy precepts in the NPF. In the NPF, as elsewhere, sustainability is understood as having three distinct dimensions economic, social and environmental - and as such it takes into account 
a wider range of considerations than just the economic. Because of this, the concept is difficult to operationalise fully, but the geographical process of commuting is of central importance. Like sustainability, commuting has economic and social, as well as environmental, dimensions, as longer commutes impose costs across all three of these domains. In this context, the growth of commuter towns in the hinterlands of all the major cities, but especially Dublin, gives grounds for concern. Twenty-nine towns were identified earlier as having transitioned up two or more levels of the urban hierarchy, twenty-two of which are located in the GDA. Using data from the 2016 census of population (CSO, 2017b, Table E6034), all but two can be classified as essentially commuter towns, in that out-commuting exceeds in-commuting. In eighteen cases, 75 per cent or more of the resident working population commutes to work from the town, and nine of these are large population centres: Ashbourne, Balbriggan, Celbridge, Greystones, Laytown-Bettystown, Leixlip, Malahide, Maynooth and Skerries. The emergence of commuter towns appears to be part of what Morgenroth (2018, p. 97) argues is a growing disjuncture, or spatial mismatch, between where people live and where they work. The consequence of this mismatch is increased commuting distances and times. Data from the CSO (2017b) show that average travel to work times increased by 6 per cent, from 26.6 to 28.2 minutes, between 2011 and 2016. Reflecting the economic recovery, there were an additional 143,757 persons travelling to work in 2016 for whom a travel time was reported, and half of these $(67,510)$ reported travel times in excess of 45 minutes. On the basis of sustainability considerations relating to commuting, the evolution of the Irish urban system since 1966 must again be assessed in a negative light.

\section{Conclusions}

This paper has examined the differential growth of urban centres in Ireland over the fifty years that have elapsed since the first attempt at national-level spatial planning, the Buchanan report of 1968. It has identified the outcome as the emergence of a decentralised form of urbanisation, based on the transformation of rural villages and small towns into large centres of population, a disproportionate number of which are located in the GDA. While this form of urbanisation might be said at least to have dampened the urban sprawl of Dublin, it has done so at the expense of creating an arguably more unsustainable form of urban development based around commuter settlements. 
Indeed the relative underperformance of the Dublin urban area in terms of population growth, as reported in this paper, may be considered more apparent than real, since an argument can be made to include the commuter settlements with the city in an extended 'metropolitan area' definition of the capital. Under such a scenario it is likely that Dublin's primacy relative to the second-tier cities would be even more pronounced than reported here. In any event, deconcentrated, decentralised urbanisation has done nothing for the development of Ireland's second-tier cities, despite their being identified in both the Buchanan report and the NSS as central to the attainment of a more spatially balanced form of development, and despite recommendations in the European spatial planning literature of the need for investment in such cities as a means of improving national economic performance.

The NPF aims to tackle the trend of unplanned and unsustainable urbanisation: it talks (Government of Ireland, 2018, p. 20) about breaking the pattern of 'business as usual' and seeking to 'disrupt trends that have been apparent for the past fifty years'. Thus, the framework envisages that, of a projected extra one million population in Ireland by 2040, roughly half will reside in the five cities. In prioritising the second-tier cities the NPF attempts to break away from the Dublin versus the rural areas binary which has underpinned so much of the debate on regional development in Ireland. This aspect of the plan is to be welcomed.

By way of conclusion, it is instructive to compare the NPF targets on population growth to actual long-term growth for the second-tier cities and, for comparison, the three NUTS 2 regions (Table 10). The fact that targeted growth for the Eastern and Midland region (consisting of Dublin, the Mid-East and the Midland regions) is below long-run historical growth is indicative of the plan's intention to reshape the country's settlement pattern. The target for the Northern and Western region, at 49 per cent above the historical annual growth rate, is ambitious, given that this region continues to have the weakest urban structure of the three. However, by far the most ambitious target is that for the second-tier cities. The NPF growth target for Cork, Limerick, Galway and Waterford is two-and-a-half times the long-term historical growth rate of these centres combined. Whether or not such ambitious targets can be realised remains to be seen, but it is clear that implementation, the weakest aspect of spatial planning to date, will have to be proactively driven. What is also clear from this 
paper is that attainment of the NPF targets is going to be considerably more difficult now than it might have been, had the proposals of either Buchanan or the NSS for selective urban development been carried through into policy and planning. Hopefully the appropriate lessons will be learned.

\section{Table 10: National Planning Framework targets in relation to historical growth rates}

\begin{tabular}{lccc}
\hline & $\begin{array}{c}\text { Growth } \\
\text { 1966-2016 } \\
\text { per annum }\end{array}$ & $\begin{array}{c}\text { NPF } \\
\text { 2016-2040 } \\
\text { (mid-estimate) } \\
\text { per annum }\end{array}$ & $\begin{array}{c}\text { Target/ } \\
\text { historical }\end{array}$ \\
\hline Ireland & 37,557 & 43,542 & 1.16 \\
Second-tier cities (4) & 3,936 & 10,000 & 2.54 \\
Eastern and Midland region & 21,832 & 21,458 & 0.92 \\
Southern region & 10,982 & 15,000 & 1.37 \\
Northern and Western region & 4,744 & 7,083 & 1.49 \\
\hline
\end{tabular}

Source: Government of Ireland (2018) and author's calculations.

\section{References}

Brady, W. (2016) Territorial development, planning reform and urban governance: The case of Ireland's second tier cities. European Planning Studies, 24 (12), 2217-40.

Cawley, M. (1991) Town population change 1971-1986: Patterns and distributional effects. Irish Geography, 24 (2), 106-16.

Clark, J., Harrison, J., \& Miguelez, E. (2018) Connecting cities, revitalising regions: The centrality of cities to regional development. Regional Studies, $52(8), 1025-8$.

Colin Buchanan and Partners. (1968) Regional studies in Ireland. Dublin: An Foras Forbartha.

Commission of the European Communities. (1999). European spatial development perspective: Towards balanced and sustainable development of the territory of the European Union. Luxembourg: Commission of the European Communities.

CSO. (1967). Census of population of Ireland 1966. Volume 1. Dublin: The Stationery Office.

CSO. (1972). Census of population of Ireland 1971. Volume 1. Dublin: The Stationery Office.

CSO. (2012). Population classified by area. Dublin: The Stationery Office.

CSO. (2017a). Census 2016 results. Profile 2 - Population distribution and movements. Retrieved from https://www.cso.ie/en/csolatestnews/press pages/2017/census2016profile2-populationdistributionandmovements/ [20 March 2019]. 
CSO. (2017b). Census 2016 results. Profile 6 - Commuting in Ireland. Retrieved from https:/www.cso.ie/en/csolatestnews/presspages/2017/census2016 profile6-commutinginireland/ [20 March 2019].

Dijkstra, L. (2013). Why investing more in the capital can lead to less growth. Cambridge Journal of Regions, Economy and Society, 6 (2), 251-68.

Dijkstra, L., Garcilazo, E., \& McCann, P. (2013). The economic performance of European cities and city regions: Myths and realities. European Planning Studies, 21 (3), 334-54.

ESPON. (2012). Second tier cities and territorial development in Europe: Performance, policies, and prospects. Retrieved from https://www.espon. eu/sites/default/files/attachments/SGPTD_Final_Report_-_Final Version_27.09.12.pdf [29 June 2019].

ESPPON. (2016). Second tier cities matter. Retrieved from https://www.espon.eu/sites/default/files/attachments/ESPON_policy_brief_ second_tier_cities_0.pdf [19 March 2019].

Flanagan, M. - G. (2010). Urban sociology. Images and structure (5th edn). Lanham, MD: Rowman and Littlefield.

Fujita, M., Krugman, P., \& Venables, A. J. (1999). The spatial economy. Cities, regions and international trade. Cambridge, MA: MIT Press.

Government of Ireland. (2002). National spatial strategy for Ireland 2002-2020: People, places and potential. Dublin: The Stationery Office.

Government of Ireland. (2018). Project Ireland 2040: The National Planning Framework. Retrieved from http:/npf.ie/wp-content/uploads/ProjectIreland-2040-NPF.pdf [14 March 2019].

Hourihan, K. (1992). Population change in Irish cities, 1981-6: County boroughs, suburbs and daily urban systems. Irish Geography, 25 (2), 160-8.

Huff, D. L., \& Lutz, J. M. (1995). Change and continuity in the Irish urban system, 1966-81. Urban Studies, 32 (1), 155-73.

Jefferson, M. (1939). The law of the primate city. Geographical Review, 29 (2), 226-32.

Lutz, J. M. (2001). Determinants of population growth in urban centres in the Republic of Ireland. Urban Studies, 38 (8), 1329-40.

McCafferty, D. (2007). Urban systems. In B. Bartley \& R. Kitchin (Eds), Understanding contemporary Ireland (pp. 57-70). London: Pluto Press.

Moore-Cherry, N. (2019). Project Ireland 2040: Business as usual or a new dawn? In M. Boyle, A. Jones, O. Sykes \& I. Wray (Eds), National spatial strategies in an age of inequality. Insights from the United Kingdom, Ireland and France. Liverpool: Heseltine Institute for Public Policy, Practice and Place, University of Liverpool.

Morgenroth, E. L. W. (2018). Prospects for Irish regions and counties. Scenarios and implications [Research series no. 70]. Dublin: ESRI.

OECD. (2006). Competitive cities in the global economy. Paris: Organisation for Economic Cooperation and Development.

O'Riordáin, S. (2013). Governance and the National Spatial Strategy: Placing spatial policy at the heart of the diagonal public service. Administration, 60 (3), 141-58. 
Parkinson, M., Meegan, R., \& Karecha, J. (2015). City size and economic performance: Is bigger better, small more beautiful or middling marvellous? European Planning Studies, 23 (6), 1054-68.

Pringle, D. G. (1980). The Irish urban system: An overview. Geographical Viewpoint, 9, 29-48.

Walsh, J. (2013). The National Spatial Strategy: Rationale, process, performance and prospects. Administration, 60 (3), 13-40.

Zipf, G. (1949). Human behavior and the principle of least effort. Cambridge, MA: Addison-Wesley. 